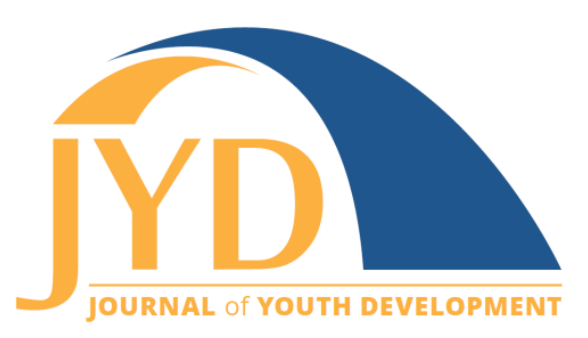

http://jyd. pitt. edu/ | Vol. 13 Issue 3 DOI 10.5195/jyd.2018.514 | ISSN 2325-4017 (online)

\title{
Improving Youth Access to Mental Health Support through a Youth-Adult Partnership
}

\author{
Laurie Ross \\ Clark University \\ Iross@clarku.edu \\ Lindsay Carpenter Connors \\ Fitchburg State University \\ lindsayjcarpenter@gmail.com
}

\begin{abstract}
Mental and behavioral health disorders are major issues facing young people in the United States; yet, the majority of youth who need support do not get help. Young people tend not to get help for 2 interacting reasons: system barriers that prevent youth from seeking help, and personal reasons that can influence them to forgo treatment. Youth-Adult Partnerships ( $Y$-APs) have the potential to improve mental health programming and increase service utilization because they create space to blend youth and service provider knowledge and experience. This article provides a detailed case study of a youth-adult partnership's 2-year community assessment and strategic planning process that led to the development of an innovative mental health model that has been sustained for 15 years. This article highlights the practices that contributed to adult transformation and the importance of adults' roles as boundary spanners in the implementation and sustainability of an intervention that addresses both system barriers and personal reasons youth forgo mental health treatment.
\end{abstract}

Key words: youth-adult partnerships, mental health

\section{Introduction}

Youth involvement in the development of health promotion programs can lead to more appropriate and effective interventions (Coates \& Howe, 2016; Reed \& Miller, 2014). Although there are many ways communities can involve young people, youth-adult partnerships (Y-APs) are particularly effective at fostering adolescent health and empowerment (Ramey, Lawford, \&

(c) $\mathrm{EY}_{\mathrm{EY}}$ New articles in this journal are licensed under a Creative Commons Attribution 4.0 License. This journal is published by the University Library System, University of Pittsburgh and is cosponsored by the University of Pittsburgh Press. The Journal of Youth Development is the official peer-reviewed publication of the National Association of Extension 4-H Agents and the National AfterSchool Association. 
Improving Youth Access to Mental Health Support

Vachon, 2017; Wong, Zimmerman, \& Parker, 2010; Zeldin, Gauley, Krauss, Kornbluh, \& Collura, 2017). Y-APs are broadly understood to be the practice of multiple youth and adults deliberating and acting together collectively; over a sustained period; through shared work; with the intention to promote social justice, strengthen organizations, and address community issues (Zeldin, Christens, \& Powers, 2013).

Adolescent mental health service delivery is a topic ripe for Y-APs. Roughly $50 \%$ of adolescents suffer from a mental health disorder; about $22 \%$ have disorders that severely impact their lives (National Institute of Mental Health, n.d.). Despite this prevalence, two thirds of youth do not get help (Merikangas et al., 2011). Youth who are racial/ethnic minorities, low-income, homeless, LGBTQ, system-involved, or male are least likely to get care (Alegria, Atkins, Farmer, Slaton, \& Stelk, 2010; Kataoka, Zhang, \& Wells, 2002; Mahalik, Good, \& Englar-Carslon, 2003; Rusch, Frazier, \& Atkins, 2015).

Young people tend not to get help for two interacting reasons (Barker, Olukoya, \& Aggleton, 2005). The first are systemic barriers to accessing treatment, which include lack of culturally competent, linguistically appropriate services; shortage of referral specialists; and inadequate insurance coverage (Alegria, Vallas, \& Pumariega, 2010). The second are personal reasons for forgoing treatment including lack of trust in mental health service providers; fear of stigmatization; a preference to rely on self, family, or friends to solve problems; and low mental health literacy (Corry \& Leavey, 2017; Garinger et al., 2016; Gulliver, Griffiths, \& Christensen, 2010; Harrison, McKay, \& Bannon, 2004; Heflinger \& Hinshaw, 2010; Kaim \& Romi, 2015; Leavey, Rothi, \& Paul, 2011; Rickwood, Deane, \& Wilson, 2007; Salerno, 2016). Untreated mental health disorders can impair daily functioning and result in long-term negative outcomes making prevention and early intervention important (Schwarz, 2009).

Y-APs can improve youth mental health programming because they create space to blend youth and service provider knowledge and experience (Burns \& Birrell, 2014; Coates \& Howe, 2016; Garinger et al., 2016; Hefferhan et al., 2017; Huggett, Flynn, Jaouich, Taylor-Gates, \& Davidson, 2017; Ramsey \& Rose-Krasnor, 2015). To contribute to the emerging knowledge base on this topic, this article provides a detailed case study of the HOPE Coalition's 2-year community assessment and strategic planning process (2000-2002) that led to the development of the HOPE Mental Health Model. The HOPE Coalition's mission is to reduce youth violence and substance abuse and promote positive mental health and youth voice through a youth-adult partnership. HOPE was founded on the idea that youth empowerment and authentic community 
Improving Youth Access to Mental Health Support

change occur in the context of shared control between youth and adults (Camino, 2005; Larson, Walker, \& Pearce, 2005; Wong et al., 2010).

The HOPE Mental Health Model integrates trained mental health counselors into communitybased youth organizations. The counselors' primary role is to build relationships with youth and staff in the organization by spending the majority of their time "on the floor"-not in an office. Once relationships are built, the counselor provides individual counseling, runs support groups and skill-building activities, and trains and supports staff on youth mental health issues. The model operates at four youth development agencies in Worcester, Massachusetts, and over the past 15 years has served more than 6,000 young people, primarily low-income youth of color.

The HOPE case study demonstrates that by drawing on youth and adult knowledge and experience, it is possible to create and sustain an intervention that addresses the system barriers and personal reasons youth forgo mental health treatment. Our primary explanation for the model's effectiveness and longevity is that the adults' preparation and experience in the youth-adult space allowed them to be effective boundary spanners in contexts in which the youth were not present (Campbell \& Erbstein, 2012; Richards-Schuster \& Timmermans, 2017). Adults' deepened understanding about youth experience increased their dedication to and willingness to implement the young people's ideas on improving adolescent mental health service delivery. Once they saw that the Model was effective, agencies and funders supported its continued implementation (Fleiszer, Semenic, Ritchie, Richer, \& Denis, 2015).

Bronfenbrenner's (1979) ecological theory of human development provides a conceptual lens to understand how Y-APs can lead to sustained community change.

\section{Adults in Y-APs and Community Change}

Research on Y-APs has identified benefits that accrue to participating youth. Examples include knowledge and skill acquisition (Kirshner, 2006; Larson \& Angus, 2011); empowerment and efficacy (Akiva, Cortina, \& Smith, 2014; Cargo, Grams, Ottoson, Ward, \& Green, 2003; Wong et al., 2010); and civic engagement (Zeldin et al., 2017). Fewer studies have examined the extent to which Y-APs lead to sustained community change (Finn \& Checkoway, 1998). Those that have focused on community change have explored how young people's involvement led to the creation of new, more effective programs (Burns \& Birrell, 2014), policy change (OgnevaHimmelberger, Ross, Burdick, \& Simpson, 2010), and culture change (Reed \& Miller, 2014). Most of these studies have focused on the Y-AP's process and short-term outputs, but not longterm community change (Richards-Schuster \& Timmermans, 2017). We know little about 
Improving Youth Access to Mental Health Support

whether initiatives produced by Y-APs are sustained beyond the intervention development period, and if they are, under what conditions.

Another understudied area in Y-APs is adult involvement. Researchers have found that an important adult attribute is the ability to connect the youth's work to community efforts (Mitra, 2005). For example, in a study of seven youth-adult partnerships, Campbell and Erbstein (2012) found that the most effective efforts were led by "boundary spanning" leaders who knew the community and were skilled at working across institutional sectors and ages. More recently, Richards-Schuster and Timmermans (2017) have discussed adults legitimizing and opening space for youth voice in traditionally adult domains. The HOPE case extends these ideas by applying Bronfenbrenner's (1979) ecological theory of human development. Specifically, Bronfenbrenner's concepts of the microsystem (i.e., the young person's immediate development contexts); the exosystem (i.e., contexts in which the young person is not immediately present, but which influence microsystems); and his explanatory proposition that if one member of a relationship undergoes development change, the other is likely to do so as well provide building blocks to understand the transformative potential of a Y-AP.

In the HOPE case, we see adults who were transformed by their experience working with youth in the youth-adult microsystem carry the youth's voice and vision into exosystems, which included an adolescent mental health task force comprised of adults, as well as the adult governance bodies of the organizations that ultimately adopted the HOPE model. We argue that this form of boundary spanning allowed young people's visions to take root in the community and permitted their ideas and knowledge to affect the community problem of youth's access to mental health services. We conclude that when adults are able to take what they gain in the $\mathrm{Y}$ AP and move into adult spaces, long-term community change can occur.

\section{Methods}

In order to understand community change and the role of adults in the HOPE Y-AP, we have constructed an in-depth case study of the coalition's formation. We chose case study research because it allows investigation of complex phenomena within its real-life context (Yin, 2003). Case study research incorporates multiple variables from various sources of evidence. This type of research can be based on a variety of data collection techniques. 
The HOPE case study was constructed through participant observation by the lead author. She has been the coalition coordinator since its inception. The included experiences and observations spanned from October 2000 through September 2002 and are based on coalitionbuilding and strategic-planning phases. Document review of her notes, quarterly funder reports, meeting agendas and minutes, youth-administered surveys and focus groups, and coalition meeting evaluations contribute to the case. Data were assembled to tell the HOPE Mental Health Model story. The article authors analyzed the story through an ecological analysis of $Y$ APs to gain an understanding of the practices and factors that could account for the long-term sustainability of the HOPE Model.

\section{Case Study Participants}

The participants in this case study are as follows:

- Coalition agencies: 14 organizations in the HOPE Coalition

- Coalition adults: The executive directors and other key staff from the 14 coalition agencies

- Coalition adult leaders: Community leaders who conceived of the HOPE Coalition and wrote the grant that started it

- Coalition staff: Coalition coordinator and three part-time youth workers

- Peer Leaders: 18 high school-aged youth who were recruited from coalition agencies

- Adolescent Mental Health Task Force: 25 adults from governmental and non-profit mental health organizations, facilitated by the HOPE Coordinator

\section{Case Study Context}

The case study is situated in Worcester, Massachusetts, the second largest city in New England. Worcester is a former industrial center that suffered from economic decline. In recent years, the city has experienced resurgence in the biomedical sector, a rebirth in its downtown, and significant population diversification. The population is estimated at 183,677; young people ages $10-24$ constitute roughly $24 \%$ of the city's population (U.S. Census Bureau, 2016). 


\section{Developing, Implementing, and Sustaining the HOPE Model}

\section{HOPE's Background}

The HOPE Coalition was born when four community leaders, concerned about youth violence and substance abuse in Worcester, applied for and received a Substance Abuse and Mental Health Services Administration (SAMHSA) Coalitions for Prevention Planning and Development grant. These four leaders, a vice president of a hospital system's community benefits department, the local YWCA executive director, a mental health organization's clinical director, and the executive director of the city's drop-in youth center, were institutionally well-positioned to facilitate dialogue and catalyze action. Commencing in October 2000, this 5-year funding opportunity incorporated a 2-year needs assessment and strategic planning phase followed by a 3-year implementation phase.

HOPE was built on an existing eight-agency collaboration that focused on citywide summer programming for middle school-aged youth. Five additional agencies were included due to their success engaging older adolescents, working with youth of color, and connecting families. The hospital system agreed to be the coalition's lead agency and fiscal sponsor during the grant period.

Coalition leadership hired a coordinator whose first task was to hire several part-time youth workers and recruit peer leaders. By January of 2001, she had recruited 18 peer leaders and three youth workers. The peer leaders were recruited from coalition members to deepen agency investment in the process. Most of the young people were Latino or African American. When the initial group of peer leaders was assembled, some school personnel expressed surprisemany of the peer leaders were by no means the recognized leaders in their schools. The HOPE youth workers were post-high school age and reflected the demographics of the youth. They helped to facilitate meetings and provided additional support to the peer leaders and the coalition coordinator.

During this recruitment phase, the four adult community leaders who secured the grant continued to play an advisory role. Working with the coalition coordinator, they developed a three-part coalition structure involving weekly peer leader meetings, quarterly Y-AP building retreats, and quarterly coalition business meetings. The next section provides an overview HOPE's first 2 years and how these meetings built the foundation to develop and sustain the HOPE Mental Health Model. 


\section{Readying the HOPE Peer Leaders and Adults}

One of the peer leaders' main roles was as research partner in the community assessment (see Kulbok et al., 2015, and Lincoln, Borg, \& Delman, 2015, for examples of youth researchers in health promotion). The peer leaders were responsible for the following:

- Develop and implement a youth needs and resources community assessment.

- Initiate discussions with peers on issues facing youth in the city and on satisfaction with existing services.

- Use assessment outcomes to develop a strategic plan.

- Attend youth-adult partnership retreats and business meetings.

The peer leaders received a stipend, food at meetings, bus vouchers, and a gym membership as compensation for their commitment to this work. Many of the peer leaders had minimal or non-existent training for this role, requiring that coalition staff be flexible and able to harness what could at times be disruptive and inconsistent behavior.

The focus over the first 6 months was threefold. The first was to build a unified peer leader team, because the young people attended different high schools and youth programs. This was done through icebreakers and team-building activities. These activities helped the youth see themselves as leaders and were meant to reign in some of their inconsistent engagement and disruptive behavior. Second, the coalition coordinator and adults from the partner agencies conducted skill-building workshops on public speaking, data gathering, meeting facilitation, planning, and goal-setting. Third, the peer leaders went to work by creating and administering surveys with hundreds of high school students on the challenges facing young people in the city, and by conducting one-on-one interviews with their peers on their perceptions of Worcester's youth programs.

The peer leaders found that the top issues facing teens were pregnancy and sexually transmitted infections, violence, stress and depression, getting into college, and drugs and alcohol. Through one-on-one interviews, peer leaders repeatedly heard about stress, depression, and anxiety. They also learned that teens coped with difficult emotions and life circumstances by engaging in risky behavior (e.g., violence, sex, substance use). Coalition staff initiated a parallel process with the executive directors of the coalition agencies through face-to-face interviews. Agency directors described a rich array of program offerings, as well as areas for desired organizational development. HOPE staff learned that agencies were committed to increasing avenues for youth voice and leadership at all levels of their 
Improving Youth Access to Mental Health Support

organizations, but many of them were unclear how to do this, or they did not feel their board members shared this commitment, or both.

\section{Youth-Adult Partnership-Building Retreats and Business Meetings}

Coalition staff recognized that the youth and adults needed guidance on how to work together in true partnership. Over the first year and a half, they held quarterly youth-adult partnership retreats designed to break down misperceptions each side had of the other, discover common ground between youth and adult experiences, and build trust so that youth and adults could work together in an atmosphere of mutual respect.

By October 2001, midway through the grant's planning phase, these retreats were used to process the peer leaders' emerging vision for mental health service delivery. In one retreat, eight youth and adults sat in the middle of the room with the peer leaders' data on mental health and simulated a discussion about how to address the problems they identified. The remaining youth and adults acted as witnesses of the process and shared their observations of how the youth and adults worked together. It was apparent that the youth and adult participants were drawing on lessons learned during prior retreats. The group balanced the discussion between the youth and the adults. The earlier retreats prepared participants to engage in effective and respectful planning work, as the following retreat evaluation comment indicated: "I see now that youth can lead groups with adults supporting them. We can work better when we know each other. We are going on the right track as a real partnership."

What was learned in these retreats became formalized at quarterly HOPE youth-adult business meetings. The group ratified the coalition mission statement, reviewed interview and survey findings, and worked toward consensus on the coalition strategic plan. Because the peer leaders facilitated the business meetings, they were powerful in nurturing agency director buyin to a youth-led process. The peer leaders prepared creative ways to deliver information, including skits and short videos. The adults were impressed by the youth's skill in relaying information and recommending solutions. The youth and adults discussed, modified, and ultimately came to agreement on the major strategies in the strategic plan. Some adult members' feedback about these meetings included:

- "The meeting went very well. I saw strong peer leaders sharing strong points."

- "This was an effective meeting involving real dialogue between young people and adult agency folks. Very articulate and respectful participants."

- "I was very impressed by the open and respectful youth-adult communication." 


\section{Action planning}

Through the business meetings and retreats, peer leaders and adults moved to a shared understanding that stress and depression were among the most important findings to emerge from the assessment. One of the coalition adult leaders responded by facilitating workshops with the peer leaders on stress and depression. Through interactive exercises and small group discussions, she worked with peer leaders to articulate their understanding of mental health, envision the type of place teens would go to for help, and describe the types of support services teens were seeking.

When describing what mental health meant to them, peer leaders conveyed a negative or stigmatized understanding and said things like: "It means you are insane, psychotic." Discussing their experiences accessing mental health services, one peer leader expressed, "You go to an office with bad music, old magazines, and have to wait in the room with an old, white, unfriendly lady knowing someone is going to get into your business." The peer leaders emphasized that services should take place in casual, comfortable settings, as one peer leader said, "Help should be in places you would want to go anyway-whether or not you have a problem! There should be music, pool tables, and games to de-stress before getting counseling." The peer leaders believed teens would be more likely to use services if they were more accessible and in places where they wanted to go, and not where they were mandated to go.

The peer leaders felt that the staff should possess a balance of "street" knowledge, personal experience, professional experience, and formal education. They strongly felt that the staff should be someone they know and trust, someone whom they interact with on a regular basiswhether or not they were experiencing problems that particular day. They talked about the importance of being able to drop in to see the person, rather than having to wait for a scheduled appointment. They felt that the services should be delivered less formally, while going for a walk, playing pool, or engaging in another activity. The peer leaders believed that having immediate access to a trusted adult, trained in mental health, would prevent more serious problems down the road.

When the peer leaders presented this vision at the next business meeting, the group realized that these types of places already existed in Worcester! What they described looked more like the local youth center or Boys \& Girls Club than a traditional mental health clinic. The challenge 
was how to integrate mental health support into these places in an invisible way that did not replicate the traditional manner of service delivery that youth found stigmatizing.

In response to this challenge, coalition staff convened the HOPE Adolescent Mental Health Task Force, consisting of 25 mental health providers and youth development professionals, to discuss the feasibility of the peer leaders' vision. Reflecting on how much work went into building the HOPE Y-AP, staff did not feel they had the time to do that work with this larger set of providers. For efficiency's sake, coalition staff decided that these would be adult meetings. While the peer leaders did not participate in these meetings, five of the task force participants were adult coalition members who had attended the youth-adult business meetings and retreats. Additionally, the coalition coordinator facilitated these meetings around the peer leaders' vision.

Over 9 months, task force members shared their experiences and difficulties providing treatment and prevention services to teens. The task force's work affirmed the youth's assessment identifying inadequate adolescent crisis intervention, referral challenges, lack of programs that focus on positive coping skills, and a shortage of bilingual/bi-cultural clinicians. Coalition staff found that the experience of teens and providers were closely aligned. The peer leaders and adults came to the simple yet powerful realization that mental health services had to be brought to the youth rather than making youth overcome system barriers to access support. Coalition youth and adults agreed that the HOPE mental health model would be a foundational element of the coalition's strategic plan.

\section{HOPE Mental Health Model Implementation and Sustainability}

By the middle of 2002, coalition staff began to forge partnership agreements for the implementation phase of the grant. Due to partners' involvement in the business meetings and retreats, these meetings went smoothly. Coalition members were asked how HOPE influenced their thinking about youth development in the city. Many agency directors had already been thinking about some of the concepts in the plan, but had not had time to put them into place, as illustrated by the following statement by a coalition member:

We had been thinking about getting youth input, but the HOPE Coalition raised its priority for the organization. In the first few meetings I was made to see the need, that it was a huge gap that we were not addressing.

Others stated that HOPE got them thinking about these issues for the first time, "I started to look at mental health; I haven't thought if it before, but it is a need of our kids." 
As the coalition was finalizing the strategic plan in spring 2002 and shifting into strategy implementation, the staff learned that SAMHSA was discontinuing the prevention coalitions in their current form. Nationwide, funding that was to go into the Implementation phase of the grant program was reallocated to a new initiative. This late notification that implementation funds would not be available was a significant challenge, leaving the coalition little time to search for other funds. The level of youth and adult engagement in the planning process and commitment to the resultant plan encouraged coalition leadership to make several important decisions. First, the hospital system that was the fiscal sponsor of the coalition agreed to house the coalition for the long term, including committing funds for the coalition coordinator's salary. Second, youth and adult coalition members prioritized continued implementation of the HOPE peer leadership program and the HOPE Mental Health Model. Third, coalition staff would work with local foundations to secure funding to implement the prioritized strategies.

Fast forward to 2018: the HOPE model operates in four youth development organizations and has served over 6,000 young people-the vast majority being low-income youth of color, with risk factors such as foster care involvement, housing instability, and gang involvement. Due to the demonstrated effectiveness of the model, local funders have committed close to $\$ 1$ million over the years, with one funder even changing guidelines to include collaborative care models that embed behavioral health services in youth organizations as a preferred service delivery system.

\section{Y-AP Practices that Contributed to Adult Transformation and Community Change}

In this discussion, we affirm that the HOPE Coalition aligns with the definition of a Y-AP. Further, we use Bronfenbrenner's concepts to explain adults' developmental change in the HOPE youth-adult microsystem that they brought into exosystems to make programming decisions. We discuss the practices that contributed to adult transformation and their roles as boundary spanning adults in the implementation and sustainability of an intervention that addressed both system barriers and personal reasons youth forgo mental health treatment.

\section{HOPE as a Youth-Adult Partnership}

The HOPE Coalition shares many attributes with Zeldin et al.'s (2013) definition of Y-APs. Through retreats and business meetings, multiple youth and multiple adults deliberated and 
acted collectively over the course of two years. Together, they analyzed and interpreted data, resulting in a strategic plan to address youth barriers to mental health services. Given racial and other disparities in who has access to mental health services, their shared work addressed a social justice issue and strengthened organizations to better serve young people.

\section{Adult Transformation in Youth-Adult Spaces}

Coalition staff's work to prepare the youth and adults to work together contributed to the adults' commitment to implementing the youth's vision for mental health service delivery. For the peer leaders, this work included fortifying their skills as researchers in areas of survey design, conducting interviews, data analysis and presenting findings (Kulbok, et al., 2015). This preparation allowed the peer leaders to collect high quality data and speak with confidence to adults. In terms of the adults' initial preparation, coalition staff conducted one-on-one interviews with them that not only gathered data on the youth service sector, but also readied them for the idea of working in partnership with youth. After working separately with youth and adults, coalition staff organized Y-AP building retreats. Individual preparation and relationship building created an environment in which youth and adults could work together in the business meetings.

\section{Boundary Spanning}

Adults' experience in the youth-adult microsystem contributed to their ability to be effective boundary spanners in the exosystems of the Adolescent Mental Health Taskforce and in their own organizations as they decided to adopt the HOPE model (Campbell \& Erbstein, 2012). Adults' deepened understanding about youths' perceptions of mental health and experiences accessing services increased the adults' dedication and willingness to implement the HOPE model.

Some might consider the work in the task force as an example of youth voice rather than a Y$\mathrm{AP}$, or even critique it as a form of ventriloquism in which adults spoke for youth (Wallerstein \& Duran, 2006). Yet, we argue that this process was fundamentally different from adults taking youth input on an adult-defined problem or a "one and done" youth focus group. HOPE peer leaders' ongoing research and analysis was at the heart of the HOPE model. Adults worked to realize the youth's vision even when young people were not present. The HOPE peer leaders proved to be an enduring force that kept the boundary spanning adults accountable. 


\section{Model Sustainability and Community Change}

In their concept analysis, Fleiszer et al. (2015) identify preconditions of healthcare innovation sustainability, including the quality of the planning process, stakeholder commitment, shared decision-making, and leadership. The HOPE case study highlights attributes of the coalition's 2year planning process that align with Fleiszer et al.'s analysis and suggest that the presence of these preconditions contributed to the implementation of a sustainable intervention. These authors identified institutionalization as an indicator of sustainability. An example of institutionalization that can be seen in the HOPE case is the funder's decision to change grant guidelines to include the core elements of the HOPE model as a preferred practice.

\section{Implications for Y-APs}

The examination of the processes and outcomes of a long-term Y-AP has implications for supporting adults, youth, other practitioners and researchers.

\section{The Need for Adults Supporting Youth in Community Change}

We may wish young people could enact their visions for community change without the assistance of boundary spanning adults. Yet, in our current service delivery systems, there will be changes that can be made only by the adults. For this reason, this case highlights the importance of involving adults in Y-APs who have access to resources and the power to enact policy and program changes.

\section{Preparation of Youth and Practitioners}

Building an enduring Y-AP that transforms community conditions requires a solid foundation. Youth workers should be ready to support youth's skill development and comfort working in partnership with adults. Likewise, adults need to be readied to work authentically with youth. This process takes time and requires different types of activities in various spaces. Lessons can be learned from the HOPE case in which there was intentional preparation for youth and adults separately. Further, youth and adults benefited from partnership building activities, such as the HOPE retreats, before attempting to work together in the HOPE business meetings. Recognizing the importance of the boundary spanning role, adults require deliberate support to carry young people's visions into broader decision-making spaces. 


\section{Implications for Research}

Researchers should examine other long-term Y-APs to explore if the factors identified in this study are relevant to other cases and what additional practices have contributed to enduring, impactful Y-APs. An important interim step would be the identification of measures that can test the extent to which Y-APs affect practitioners' attitudes about youth involvement and their willingness to implement practices created through Y-APs.

\section{Limitations}

A limitation of this research is that it is based on the planning years of one long-term Y-AP. The sample of one raises questions about the generalizability of our findings. Additionally, the case study's focus on the coalition's first two years may exclude other possible explanations for the model's longevity. In spite of these limitations, the HOPE case offers a detailed discussion of the process of forging a sustained Y-AP and highlights the adults' role, which is often underanalyzed. The empirical findings are supported by Bronfenbrenner's conceptual understanding of developmental spaces and relationships. Having an in-depth empirical analysis of the formation of a long-term Y-AP supported by a conceptually robust framework tempers these limitations, increasing the case's usefulness to communities considering developing Y-APs.

\section{Conclusion}

Youth's lack of access to mental health services is considered an intractable community problem. HOPE peer leaders and adults worked together to conceive, implement, and sustain an effective solution. Interestingly, the HOPE model enacts what the field increasingly recognizes is needed: the integration of mental health support into natural settings for youth, such as schools, online, and community-based youth development organizations (Atkins \& Lakind, 2013; Frazier, Capella, \& Atkins, 2007; Hedemann \& Frazier, 2017; Rickwood, Mazzer, \& Telford, 2015; Salerno, 2016).

We conclude that when adults are able to take what they gain in a Y-AP and move into adult spaces, community change can occur. We have attempted to make visible the processes and practices of youth-adult partnerships that allow participants to come to collective understanding about a community issue and create lasting impact. The lessons from this case study can help other initiatives create Y-APs to address other seemingly intractable problems. Having the 
Improving Youth Access to Mental Health Support

opportunity to analyze the processes that created the HOPE Mental Health Model can be instructive to other Y-APs that are just embarking on their work.

\section{References}

Akiva, T., Cortina, K., \& Smith, C. (2014). Involving youth in program decision-making: How common and what might it do for youth? Journal of Youth and Adolescence, 43(11), 1844-1860. doi: 10.1007/s10964-014-0183-y

Alegría M., Atkins, M., Farmer, E., Slaton E., \& Stelk, W. (2010). One size does not fit all: Taking diversity, culture and context seriously. Administration and Policy in Mental Health and Mental Health Services Research, 37(1-2), 48-60. doi: 10.1007/s10488-010-0283-2

Alegría, M., Vallas, M., \& Pumariega, A. (2010). Racial and ethnic disparities in pediatric mental health. Child \& Adolescent Psychiatric Clinics of North America, 19, 759-774. doi: 10.1016/j.chc.2010.07.001

Atkins, M. S., \& Lakind, D. (2013). Usual care for clinicians, unusual care for their clients: Rearranging priorities for children's mental health services. Administration and Policy in Mental Health and Mental Health Services Research, 4O(1), 48-51. doi: 10.1007/s10488-012-0453-5

Barker G., Olukoya A., \& Aggleton, P. (2005). Young people, social support and help-seeking. International Journal of Adolescent Medicine and Health, 17(4), 315-335. doi: 10.1515/IJAMH.2005.17.4.315

Bronfenbrenner, U. (1979). The ecology of human development: Experiments by nature and design. Cambridge, MA: Harvard University Press.

Burns, J,. \& Birrell, E. (2014). Enhancing early engagement with mental health services by young people. Psychology Research and Behavior Management, 7, 303-312. doi: 10.2147/PRBM.S49151

Camino, L. (2005). Pitfalls and promising practices of youth-adult partnerships: An evaluator's reflections. Journal of Community Psychology, 33(1), 75-85. doi: 10.1002/jcop.20043

Campbell, D., \& Erbstein, N. (2012). Engaging youth in community change: Three key implementation principles. Community Development, 43(1), 63-79. doi: 10.1080/15575330.2011.645042

Cargo, M., Grams, G. D., Ottoson, J. M., Ward, P., \& Green, L. W. (2003). Empowerment as fostering positive youth development and citizenship. American Journal of Health Behavior, 27, S66-s79. Retrieved from http://researchoutputs.unisa.edu.au/1959.8/130904

Coates, D., \& Howe, D. (2016). Integrating a youth participation model in a youth mental health service: Challenges and lessons learned. Child \& Youth Services, 373), 1-27.doi: 10.1080/0145935X.2015.1119652 
Corry, D. A. S., \& Leavey, G. (2017). Adolescent trust and primary care: Help-seeking for emotional and psychological difficulties. Journal of Adolescence, 54, 1-8. doi:

10.1016/j.adolescence.2016.11.003

Finn, J., \& Checkoway, B. (1998). Young people as competent community builders: A challenge to social work. Social Work, 4, 335-345. doi: 10.1093/sw/43.4.335

Fleiszer, A. R., Semenic, S. E., Ritchie, J. A., Richer, M. C., \& Denis, J. L. (2015). The sustainability of healthcare innovations: A concept analysis. Journal of Advanced Nursing, 71(7), 1484-1498. doi: 10.1111/jan.12633

Frazier, S. L., Cappella, E., \& Atkins, M. S. (2007). Linking mental health and after school systems for children in urban poverty: Preventing problems, promoting possibilities. Administration and Policy in Mental Health and Mental Health Services Research, 34(4), 389-399. doi: 10.1007/s10488-0070118-y

Garinger, C. A., Reynolds, K. A., Walker, J. R., Firsten-Kaufman, E., Raimundo, A. S., Fogarty, P. C., \& Leonhart, M. (2016). Mobilizing minds: Integrated knowledge translation and youth engagement in the development of mental health information resources. Gateways: International Journal of Community Research and Engagement, 9(1), 172-185. doi: 10.5130/ijcre.v9i1.4415

Gulliver, A., Griffiths, K., \& Christensen, H. (2010). Perceived barriers and facilitators to mental health help-seeking in young people: A systematic review. BMC Psychiatry, 101), 113-122. doi: $10.1186 / 1471-244 X-10-113$

Harrison, M. E., McKay, M. M., \& Bannon, W. M. (2004). Inner-city child mental health service use: The real question is why youth and families do not use services. Community Mental Health Journal, 4O(2), 119-131. doi: 10.1023/B:COMH.0000022732.80714.8b

Hedemann, E. R., \& Frazier, S. L. (2017). Leveraging after-school programs to minimize risks for internalizing symptoms among urban youth: Weaving together music education and social development. Administration and Policy in Mental Health and Mental Health Services Research, 44(5), 756-770. doi: 10.1007/s10488-016-0758-x

Heffernan, O. S., Herzog, T. M., Schiralli, J. E., Hawke, L. D., Chaim, G., \& Henderson, J. L. (2017). Implementation of a youth-adult partnership model in youth mental health systems research: Challenges and successes. Health Expectations, 20(6), 1183-1188. doi: 10.1111/hex.12554

Heflinger, C. A., \& Hinshaw, S. P. (2010). Stigma in child and adolescent mental health services research: Understanding professional and institutional stigmatization of youth with mental health problems and their families. Administration and Policy in Mental Health and Mental Health Services Research, 3入1-2), 61-70. doi: 10.1007/s10488-010-0294-z

Huggett, D., Flynn, A., Jaouich, A., Taylor-Gates, M., \& Davidson, S. (2017). Engaging youth in a mental health system improvement initiative in Ontario: Developing the Be Safe resource. Canadian Journal of Community Mental Health, 36(Special Issue), 121-131. doi: 10.7870/cjcmh-2017-019 
Journal of Youth Development | http://jyd.pitt.edu/ | Vol. 13 Issue 3 DOI 10.5195/jyd.2018.514

Improving Youth Access to Mental Health Support

Kaim, Z., \& Romi, S. (2015). Adolescents at risk and their willingness to seek help from youth care workers. Children \& Youth Services Review, 53, 17-23. doi: 10.1016/j.childyouth.2015.03.002

Kataoka, S. H., Zhang, L., \& Wells, K. B. (2002). Unmet need for mental health care among US children: Variation by ethnicity and insurance status. American Journal of Psychiatry, 159(9), 1548-1555. doi: 10.1176/appi.ajp.159.9.1548

Kirshner, B. (2006). Apprenticeship learning in youth activism. In P. Noguera, S. Ginwright, \& J. Cammarrota (Eds.), Beyond resistance: Youth activism and community change: New democratic possibilities for policy and practice for America's youth (pp. 37-57). Oxford, UK: Routledge.

Kulbok, P. A., Meszaros, P. S., Bond, D. C., Thatcher, E., Park, E., Kimbrell, M., \& Smith-Gregory, T. (2015). Youths as partners in a community participatory project for substance use prevention. Family \& Community Health, 38(1), 3-11. doi:_10.1097/FCH.0000000000000061

Larson, R., \& Angus, R. (2011). Adolescents' development of skills for agency in youth programs: Learning to think strategically. Child Development, 82, 277-294. doi: 10.1111/j.14678624.2010.01555.x

Larson, R., Walker, K., \& Pearce, N. (2005). A comparison of youth-driven and adult-driven youth programs: Balancing inputs from youth and adults. Journal of Community Psychology, 33, 57-74. doi: $10.1002 /$ jcop.20035

Leavey, G., Rothi, D., \& Paul, R. (2011). Trust, autonomy and relationships: The help-seeking preferences of adolescents in secondary level schools in London (UK). Journal of Adolescence, 34, 685-693. doi: 10.1016/j.adolescence.2010.09.004

Lincoln, A. K., Borg, R., \& Delman, J. (2015). Developing a community-based participatory research model to engage transition age youth using mental health service in research. Family $\&$ Community Health, 38(1), 87-97. doi: 10.1097/FCH.0000000000000054

Mahalik, J. R., Good, G. E., \& Englar-Carlson, M. (2003). Masculinity scripts, presenting concerns, and help seeking: Implications for practice and training. Professional Psychology: Research and Practice, 34(2), 123. doi: 10.1037/0735-7028.34.2.123

Merikangas, K., He, J., Burstein, M., Swendsen, J., Avenevoli, S., Case, B., . . Olfson, M. (2011). Service utilization for lifetime mental disorders in US adolescents: Results of the National Comorbidity Survey-Adolescent Supplement (NCS-A). Journal of the American Academy of Child \& Adolescent Psychiatry, 50(1), 32-45. doi: 10.1016/j.jaac.2010.10.006

Mitra, D. L. (2005). Adults advising youth: Leading while getting out of the way. Educational Administration Quarterly, 41(3), 520-553. doi: 10.1177/0013161X04269620

National Institute of Mental Health. (n.d.). Mental illness statistics. Retrieved from https://www.nimh.nih.gov/health/statistics/mental-illness.shtml

Ogneva-Himmelberger, Y., Ross, L., Burdick, W., \& Simpson, S. A. (2010). Using geographic information systems to compare the density of stores selling tobacco and alcohol: Youth making an argument 
Improving Youth Access to Mental Health Support

for increased regulation of the tobacco permitting process in Worcester, Massachusetts, USA. Tobacco Control, 19(6), 475-480. doi: 10.1136/tc.2008.029173

Ramey, H. L., Lawford, H. L., \& Vachon, W. (2017). Youth-adult partnerships in work with youth: An overview. Journal of Youth Development, 12(4), 38-60. doi: 10.5195/jyd.2017.520

Ramsey, H., \& Rose-Krasnor, L. (2015). The new mentality: Youth-adult partnerships in community mental health promotion. Children and Youth Services Review, 50, 28-37. doi: 10.1016/j.childyouth.2015.01.006

Reed, S., \& Miller, R. (2014). The benefits of youth engagement in HIV-preventive structural change interventions. Youth \& Society, 46(4), 529-547. doi: 10.1177/0044118X12443372

Richards-Schuster, K., \& Timmermans, R. (2017). Conceptualizing the role of adults within youth-adult partnerships: An example from practice. Children and Youth Services Review, 81, 284-292. doi: 10.1016/j.childyouth.2017.07.023

Rickwood, D. J., Deane, F. P., \& Wilson, C. J. (2007). When and how do young people seek professional help for mental health problems? Medical Journal of Australia, 187(7), S35-9.

Rickwood, D. J., Mazzer, K. R., \& Telford, N. R. (2015). Social influences on seeking help from mental health services, in-person and online, during adolescence and young adulthood. BMC Psychiatry, 15(1), 40. doi: 10.1186/s12888-015-0429-6

Rusch, D., Frazier, S. L., \& Atkins, M. (2015). Building capacity within community-based organizations: New directions for mental health promotion for Latino immigrant families in urban poverty. Administration and Policy in Mental Health and Mental Health Services Research, 42(1), 1-5. doi: $10.1007 /$ s10488-014-0549-1

Salerno, J. (2016). Effectiveness of universal school-based mental health awareness programs among youth in the United States: A systematic review. Journal of School Health, 86(12), 922-931. doi: 10.1111/josh. 12461

Schwarz, S. W. (2009). Adolescent mental health in the United States: Facts for policymakers. New York, NY: National Center for Children in Poverty (NCCP) Mailman School of Public Health Columbia University.

U.S. Census Bureau, 2012-2016 American Community Survey 5-Year Estimates. Retrieved from https://factfinder.census.gov/faces/tableservices/jsf/pages/productview.xhtml?pid=ACS_16_5YR_ S0101\&prodType $=$ table

Wallerstein, N. B., \& Duran, B. (2006). Using community-based participatory research to address health disparities. Health Promotion Practice, 73$), 312-323$. doi: 10.1177/1524839906289376

Wong, N., Zimmerman, M., \& Parker, E. (2010). A typology of youth participation and empowerment for child and adolescent health promotion. American Journal of Community Psychology, 46, 100-114. doi: 10.1007/s10464-010-9330-0

Yin, R. K. (2003). Case Study Research. Sage Publications: Thousand Oaks, CA. 
Journal of Youth Development | http://jyd.pitt.edu/ | Vol. 13 Issue 3 DOI 10.5195/jyd.2018.514 Improving Youth Access to Mental Health Support

Zeldin, S., Christens, B. D., \& Powers, J. L. (2013). The psychology and practice of youth-adult partnership: Bridging generations for youth development and community change. American Journal of Community Psychology, 51(3-4), 385-397. doi: 10.1007/s10464-012-9558-y.

Zeldin, S., Gauley, J., Krauss, S. E., Kornbluh, M., \& Collura, J. (2017). Youth-adult partnership and youth civic development: Cross-national analyses for scholars and field professionals. Youth \& Society, 49(7), 851-878. doi: 10.1177/0044118X15595153 